\title{
CDK8-Mediated STAT1-S727 Phosphorylation Restrains NK Cell Cytotoxicity and Tumor Surveillance
}

\author{
Eva Maria Putz,, Dagmar Gotthardt, ${ }^{1}$ Gregor Hoermann, ${ }^{2}$ Agnes Csiszar, ${ }^{3}$ Silvia Wirth, ${ }^{3}$ Angelika Berger, ${ }^{1}$ \\ Elisabeth Straka, ${ }^{1}$ Doris Rigler, ${ }^{4}$ Barbara Wallner, ${ }^{4}$ Amanda M. Jamieson, ${ }^{5}$ Winfried F. Pickl, ${ }^{6}$ Eva Maria Zebedin-Brandl, ${ }^{7}$ \\ Mathias Müller, ${ }^{4}$ Thomas Decker, ${ }^{5}$ and Veronika Sexl ${ }^{1, *}$ \\ 1 Institute of Pharmacology and Toxicology, Department for Biomedical Sciences, University of Veterinary Medicine Vienna, 1210 \\ Vienna, Austria \\ ${ }^{2}$ Department of Laboratory Medicine, Medical University of Vienna, 1090 Vienna, Austria \\ ${ }^{3}$ Research Institute of Molecular Pathology, 1030 Vienna, Austria \\ ${ }^{4}$ Institute of Animal Breeding and Genetics, Department for Biomedical Sciences, University of Veterinary Medicine Vienna, 1210 \\ Vienna, Austria \\ ${ }^{5}$ Max F. Perutz Laboratories, University of Vienna, 1030 Vienna, Austria \\ 'Institute of Immunology, Medical University of Vienna, 1090 Vienna, Austria \\ ${ }^{7}$ Institute of Pharmacology, Center for Physiology and Pharmacology, Medical University of Vienna, 1090 Vienna, Austria \\ *Correspondence: veronika.sex|@vetmeduni.ac.at \\ http://dx.doi.org/10.1016/j.celrep.2013.07.012 \\ This is an open-access article distributed under the terms of the Creative Commons Attribution-NonCommercial-No Derivative Works \\ License, which permits non-commercial use, distribution, and reproduction in any medium, provided the original author and source are \\ credited.
}

\section{SUMMARY}

The transcription factor STAT1 is important in natural killer (NK) cells, which provide immediate defense against tumor and virally infected cells. We show that mutation of a single phosphorylation site (Stat1-S727A) enhances NK cell cytotoxicity against a range of tumor cells, accompanied by increased expression of perforin and granzyme B. Stat1S727A mice display significantly delayed disease onset in NK cell-surveilled tumor models including melanoma, leukemia, and metastasizing breast cancer. Constitutive phosphorylation of S727 depends on cyclin-dependent kinase 8 (CDK8). Inhibition of CDK8-mediated STAT1-S727 phosphorylation may thus represent a therapeutic strategy for stimulating NK cell-mediated tumor surveillance.

\section{INTRODUCTION}

Signal transducer and activator of transcription 1 (STAT1) is activated downstream of interferons (IFNs) and transmits antiviral and antimicrobial signals from the cell surface to the nucleus (Stark and Darnell, 2012). Mice with complete or tissue-specific loss of Stat1 are prone to succumb to infections and to develop tumors (Kaplan et al., 1998; Klover et al., 2010; Schneckenleithner et al., 2011; Koromilas and Sexl, 2013). STAT1 activity is regulated posttranscriptionally, e.g., by JAK-mediated phosphorylation of tyrosine701 (Y701), which allows STAT1 dimerization and nuclear translocation. Various kinases phosphorylate STAT1's transactivation domain at serine727 (S727) (Kovarik et al., 1999; Nair et al., 2002; Deb et al., 2003; Bancerek et al., 2013). IFN-induced S727 phosphorylation occurs after STAT1 dimers bind to DNA (Sadzak et al., 2008) and modulates transcription (Wen et al., 1995). Knockin mice with point-mutated STAT1-S727 (Stat1-S727A) display reduced antimicrobial activity, emphasizing the importance of the phosphorylation site and suggesting that the $S 727 A$ mutation generates a hypomorphic Stat1 allele (Varinou et al., 2003; Pilz et al., 2009).

Natural killer (NK) cells are important in the defense against virally infected and malignant cells (Vivier et al., 2011). Their development, activation, and cytotoxic function are tightly regulated by cytokines, which induce the JAK/STAT signaling pathway. Interleukins 2 and 15 (IL-2 and IL-15) drive NK cell development, proliferation, and homeostasis and signal predominantly via STAT5 (Lodolce et al., 1998). STAT1, STAT3, and STAT4 are downstream of IL-12, mediating NK cell activation and cytotoxicity and triggering the transcription of IFN- $\gamma$, granzymes, and perforin (Watford et al., 2004). IFN type I induces NK cell cytotoxicity in viral infections and stimulates NK cell proliferation and survival via activation of dendritic cells (DCs) (Nguyen et al., 2002; Lucas et al., 2007).

Although STAT1 regulates many aspects of NK cell biology (Lee et al., 2000; Kovacic et al., 2006), the role of STAT1-S727 phosphorylation in NK cells is unknown. We show that in Stat1-S727A mutant mice, NK cells display higher cytotoxicity toward a broad panel of target cells, leading to more efficient tumor clearance. The upstream kinase is CDK8, which offers a therapeutic opportunity to stimulate NK cell activity.

\section{RESULTS}

High Cytotoxic Activity of Stat1-S727A NK Cells

Stat1-S727A mice exhibit slightly elevated numbers of mature NK cells ( $\mathrm{mNKs}$ ) in bone marrow, spleen, and blood (Figures $1 \mathrm{~A}$ and $1 \mathrm{~B}$ ) not paralleled by enhanced numbers of NK cell precursors (Figure 1A) nor by increased proliferation (data not shown). Unlike the situation in Stat ${ }^{-/-}$NK cells, maturation of 
A

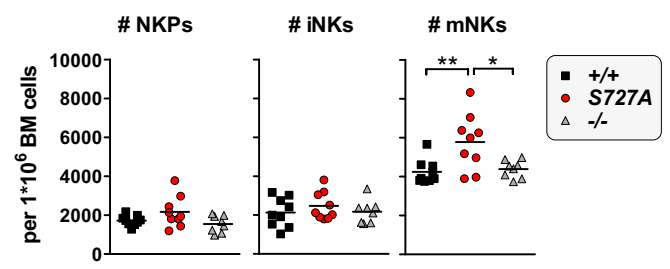

C

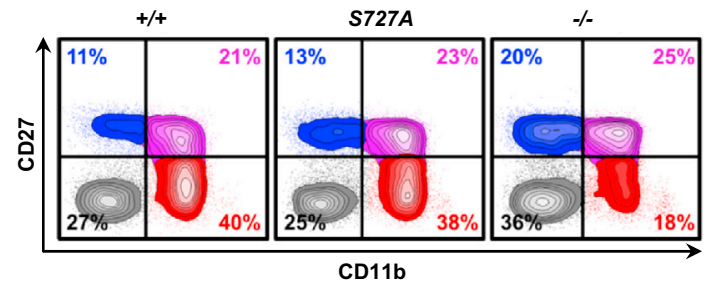

E

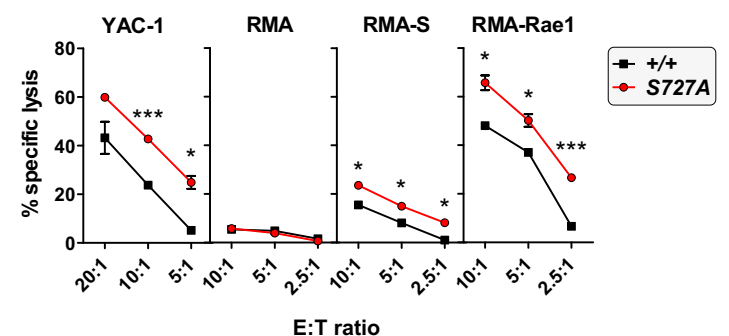

G

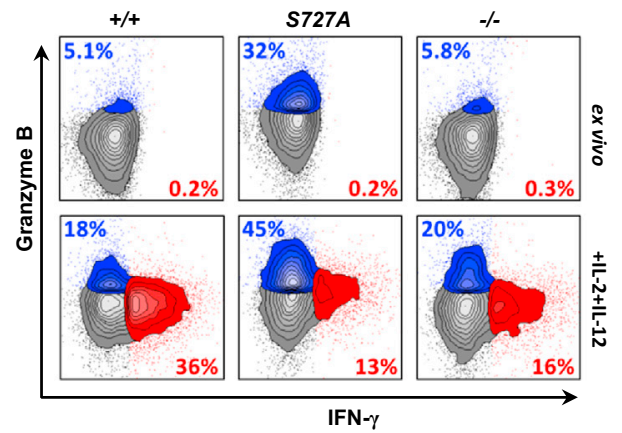

B

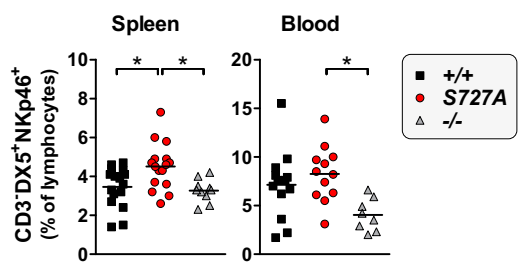

D

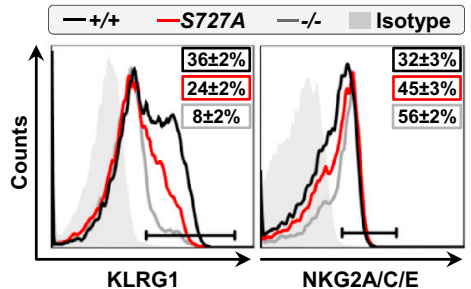

F

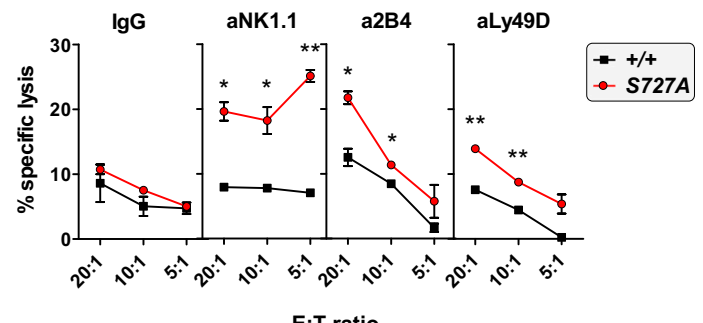

H

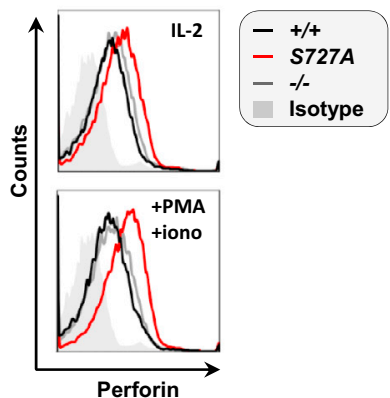

Figure 1. Presence, Development, and Cytotoxic Function of Stat1-S727A NK Cells

(A) Bone marrow was investigated for NK cell precursors (NKPs, CD3 ${ }^{-}$Ter- $119^{-} \mathrm{GR}^{-} \mathrm{B}^{-} 20^{-} \mathrm{CD} 122^{+} \mathrm{NK} 1.1^{-} \mathrm{DX} 5^{-}$), immature $\mathrm{NK}$ cells (iNKs, CD3 ${ }^{-}$Ter$\left.119^{-} \mathrm{GR}^{-}{ }^{-} \mathrm{B} 220^{-} \mathrm{CD} 122^{+} \mathrm{NK} 1.1^{+} \mathrm{DX} 5^{-}\right)$, and mNKs (CD3 ${ }^{-}$Ter- $\left.119^{-} \mathrm{GR} 1^{-} \mathrm{B} 220^{-} \mathrm{CD} 122^{+} \mathrm{NK} 1.1^{+} \mathrm{DX} 5^{+}\right)$. Each symbol represents an individual mouse; small horizontal lines indicate the mean $\left({ }^{*} p<0.05,{ }^{* *} p<0.01\right.$; one-way ANOVA and Tukey's post hoc test).

(B) Number of CD3 ${ }^{-} \mathrm{DX} 5^{+} \mathrm{NKp} 46^{+} \mathrm{NK}$ cells, given as percentages of spleen and blood lymphocytes, is shown. Each symbol represents an individual mouse; horizontal lines indicate the mean ( ${ }^{*} \mathrm{p}<0.05$; one-way ANOVA and Tukey's post hoc test).

(C) NK cell maturation profiles represented by the expression of CD27 and CD11b on CD3 ${ }^{-} \mathrm{NK} 1.1^{+}$splenocytes are shown. Data are representative for at least five independent experiments with $n>10$ for each genotype.

(D) Expression of KLRG1 and NKG2A/C/E on CD3 ${ }^{-} \mathrm{DX} 5^{+} \mathrm{NK} 1.1^{+} \mathrm{NKp} 46^{+}$splenocytes is shown. Numbers indicate the percentage of gate ${ }^{+}$(horizontal line) NK cells \pm SEM; $n \geq 9$ for each genotype.

(E) Cytotoxicity of wild-type versus Stat1-S727A NK cells against YAC-1, RMA, RMA-S, and RMA-Rae1 tumor targets at given effector-to-target (E:T) ratios, measured in a $4 \mathrm{hr}\left[{ }^{51} \mathrm{Cr}\right]-$-release cytotoxicity assay is shown. Symbols represent means, and error bars indicate SEM of triplicates ${ }^{*} \mathrm{p}<0.05$, ${ }^{\star * *} \mathrm{p}<0.001$; unpaired $t$ test). Data are representative of three independent experiments.

(F) R-ADCC against FcR ${ }^{+}$Daudi target cells crosslinked with antibodies against NK1.1, 2B4, and Ly49D is shown. Symbols represent means, and error bars indicate SEM of triplicates $\left({ }^{*} \mathrm{p}<0.05,{ }^{* *} \mathrm{p}<0.01\right.$; unpaired t test). Data are representative of two independent experiments.

(G) IFN- $\gamma$ and granzyme B protein expression in splenic NK cells (gated on CD3 ${ }^{-} \mathrm{NKp} 46^{+}$) ex vivo and after $4 \mathrm{hr}$ stimulation with IL-2 and IL-12 is presented. $(\mathrm{H})$ LAK cells stained intracellularly for perforin under normal culturing conditions and after $4 \mathrm{hr}$ treatment with PMA and ionomycin are shown.

See also Figure S1 and Table S1. 
Stat1-S727A NK cells is unaffected (Figure 1C). Consistent with previous findings by Robbins et al. (2005), Stat $1^{-/-}$peripheral NK cells have an immature phenotype (Figures 1C and 1D; Table S1). In contrast, changes on Stat1-S727A cells are minor: only the relative increase of $\mathrm{NKG} 2 \mathrm{~A} / \mathrm{C} / \mathrm{E}^{+}$and a reduction of $\mathrm{KLRG} 1^{+} \mathrm{NK}$ cells (Figure 1D; Table S1) are consistently observed despite normal levels of MHC class I (data not shown).

Unexpectedly, purified and in vitro-expanded NK cells derived from Stat1-S727A mice show significantly higher cytotoxicity toward YAC-1, RMA-S, and RMA-Rae1 target cells (Figure 1E). Redirected antibody-dependent cellular cytotoxicity (R-ADCC) against the receptors NK1.1, 2B4, and Ly49D confirmed this finding (Figure 1F).

IL-12 is a potent activator of NK cell cytotoxicity and induces the transcription of granzymes, perforin, and IFN- $\gamma$ (Watford et al., 2004; Figure S1). I/12p40 expression is enhanced in Stat1-S727A bone marrow-derived macrophages upon CpG treatment (Schroder et al., 2007). We failed to detect any differences in $/ 12 p 40$ expression under basal conditions. Stimulation with LPS increased $/ 112 p 40$ expression in Stat1-S727A splenocytes less than in wild-type cells (Figure S2), showing that enhanced NK cell cytotoxicity in Stat1-S727A mice is not caused by higher IL-12 levels. IL-12-dependent STAT activation is comparable in wild-type and Stat1-S727A NK cells (Figures 2 and S2). Surprisingly, we found reduced IFN- $\gamma$ production upon IL12 stimulation in Stat $^{-1-}$ and Stat1-S727A NK cells (Figures $1 \mathrm{G}$ and S1): Stat1-S727A mutation can thus phenocopy some aspects of Stat1 deficiency. In contrast, granzyme B expression is significantly enhanced in primary Stat1-S727A NK cells, both without and after stimulation by IL-2 and IL-12 (Figure 1G). Levels of perforin are enhanced under standard culturing conditions and especially after stimulation with PMA and ionomycin (Figure $1 \mathrm{H}$ ). The increased amounts of granzyme $\mathrm{B}$ and perforin correlate with changes in the levels of microRNA-378 and -30e, which posttranscriptionally regulate the two enzymes, respectively (Wang et al., 2012) (see Extended Results; Figure S1).

\section{Constitutive Basal Phosphorylation on STAT1-S727 Is Mediated by CDK8}

In contrast to $\mathrm{Y} 701, \mathrm{~S} 727$ is constitutively phosphorylated in unstimulated wild-type NK cells (Figures 2A-2C). In lymphokine-activated killer (LAK) cells, STAT1-S727 phosphorylation is enhanced by IFN- $\beta$ or IL-12 (Figures $2 \mathrm{~B}$ and $2 \mathrm{C}$ ). In line with previous reports by Bromberg et al. (1996) and Horvath and Darnell (1996), lack of S727 phosphorylation does not interfere with IFN- $\beta$-mediated transcription of typical STAT1 target genes (Figure S2).

Web-based inquiries to identify the STAT1-S727 kinase gave the highest support vector machine (SVM) scores for cyclindependent kinases (CDKs) and mitogen-activated protein kinases (MAPKs). The pan-CDK inhibitor flavopiridol strongly reduces STAT1-S727 phosphorylation, whereas roscovitine, which inhibits CDK1, CDK2, CDK5, CDK7, and CDK9, has no impact. Similarly, the p38 MAPK inhibitor BIRB 0796 reduces STAT1-S727 phosphorylation, but the prototypic p38 inhibitor SB 203580 does not (Figure 2D). We performed knockdown of CDK8, a kinase targeted by both flavopiridol and BIRB 0796 (Davis et al., 2011), in primary NK cells and found a reduction of STAT1-S727 phosphorylation (Figure 2E). The lifespan of primary NK cells is limited, so we generated immortalized primary murine NK cells from mice with a disrupted Ink4a tumor suppressor locus (Serrano et al., 1996). The immortalized NK cells retain their growth dependence on IL-2 and their functionality with respect to IFN- $\gamma$ production and cytotoxicity for several months (Figure S2). CDK8 knockdown in the Ink4a ${ }^{-1-} \mathrm{NK}$ cells verified the link between CDK8, STAT1-S727 phosphorylation and enhanced cytotoxicity (Figures $2 \mathrm{~F}$ and $2 \mathrm{G}$ ). Attempts to inhibit CDK8 in primary NK cells and to test the resulting cytotoxicity were inconclusive because there is still no inhibitor specific for CDK8. Inhibitors target multiple kinases, and this renders an interpretation of the assays impossible.

\section{Stat1-S727A Mice Are Less Susceptible to NK Cell- Surveilled Tumors}

To examine whether the increased cell-mediated cytotoxicity associated with the Stat1-S727A mutation confers enhanced protection against NK cell-surveilled tumors, we used B16F10 melanoma cells, which form tumor nodules in the lung upon intravenous injection. In Stat $1^{-/-}$animals, the first nodules were detected as early as 7 days postinjection. Wild-type animals showed the first tumors after 14 days, whereas Stat1S727A mice remained free of visible tumor nodules until day 21 (Figures $3 A$ and $3 B$ ). The enhanced resistance of Stat1-S727A mice to B16F10 tumor formation led to a significant increase in overall survival (Figure $3 \mathrm{C}$ ).

We also injected wild-type, Stat $1^{-/-}$, and Stat1-S727A mice intravenously with $v$-ab/-transformed leukemic cells, which are eradicated by NK cells (Stoiber et al., 2004). Stat $1^{-1-}$ mice rapidly succumb to leukemia, but Stat1-S727A animals are significantly less susceptible (Figure 3D). As a control, we used Rag2 $^{-/}$/Stat1-S727A mice that lack B and T lymphocytes (Figure $3 \mathrm{E})$. The survival curves of Rag2 $^{-1-}$ and Rag2 ${ }^{-1-} /$ Stat1$S 727 A$ mice are superimposable with those of wild-type and Stat1-S727A mice. Disease severity at the day of sacrifice was comparable (Figure S3).

Metastasis represents a major problem in cancer therapy. In the 4T1-induced cancer model, the growth of the primary breast tumor is NK cell independent, whereas its ability to metastasize is restricted by NK cell-mediated tumor surveillance. Wild-type mice, Stat $1^{-/-}$mice, and mice with the Stat1S727A mutation showed no differences in volume or weight of primary tumors (Figures $4 \mathrm{~A}$ and $4 \mathrm{~B}$ ). We also monitored white blood cell (WBC) counts and the appearance of myeloid-derived suppressor cells (MDSCs, defined as $\mathrm{GR} 1^{+} \mathrm{CD} 11 \mathrm{~b}^{+}$) in the blood, surrogate markers of disease severity. Despite comparable growth rates of the primary tumors, WBC and MDSC counts were significantly enhanced in Stat $1^{-1-}$ mice from day 21. After 31 days, WBC and MDSC counts markedly increased in wildtype mice but stayed clearly lower in Stat1-S727A mice (Figures $4 C$ and 4D). The lungs of all diseased mice were investigated for metastatic infiltrates. As expected, Stat $1^{-1-}$ mice had dense tumor cell infiltration in their lungs. At day 31 postinoculation, wildtype animals had significantly enhanced lung weights and severe metastatic burden, whereas Stat1-S727A mice were completely metastasis-free (Figures 4E-4G). To confirm the impact of NK cell-mediated tumor surveillance of $4 \mathrm{~T} 1$ 
A

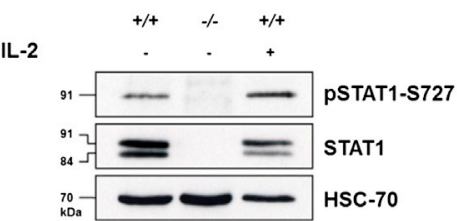

B
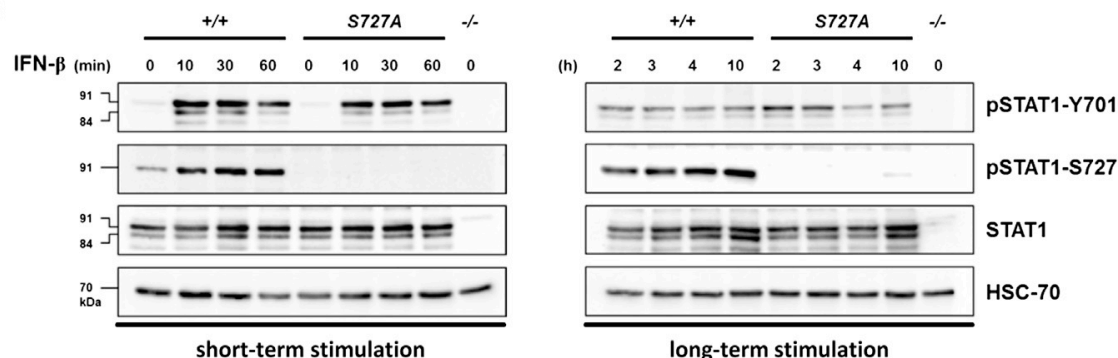

C
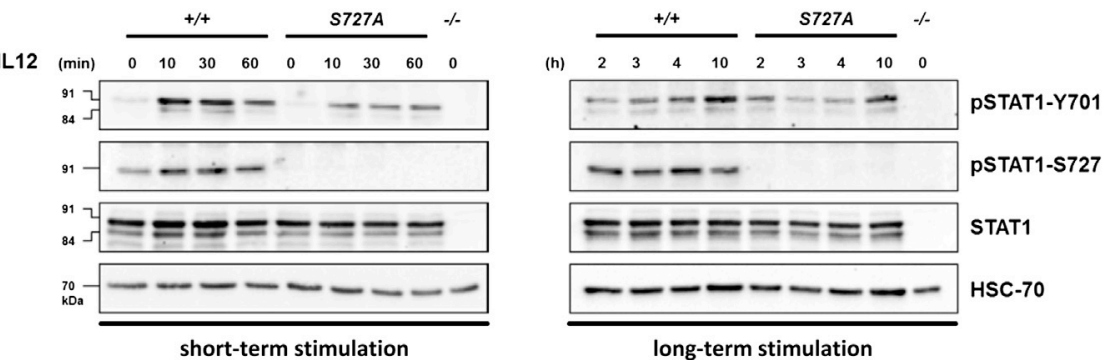

long-term stimulation

D

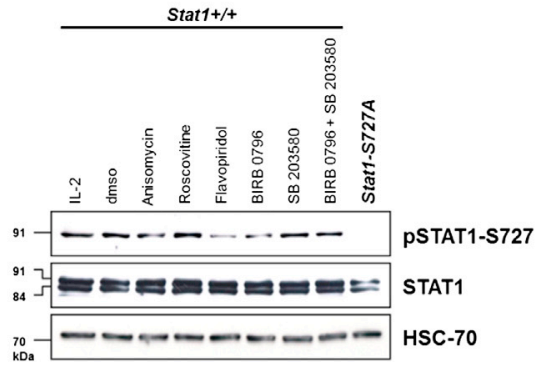

E

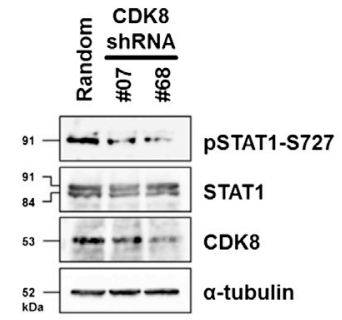

F

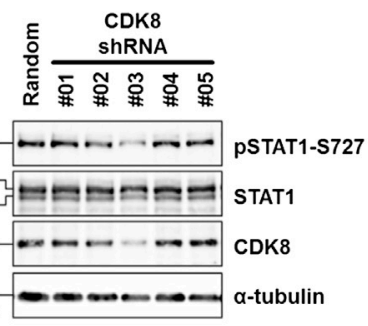

G

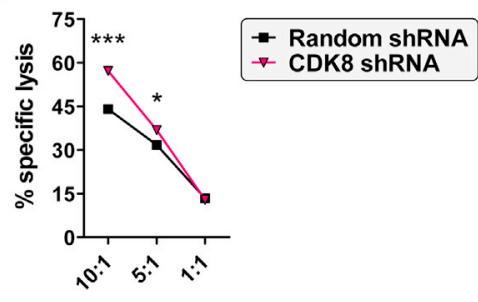

E:T ratio

Figure 2. Constitutive Basal STAT1-S727 Phosphorylation in NK Cells Is Mediated by CDK8

(A) Western blot of freshly isolated DX5 $5^{+}$splenocytes from wild-type animals shows constitutive basal phosphorylation on STAT1-S727 in vivo.

(B and C) In vitro-expanded LAK cells from wild-type and Stat1-S727A mice were treated with or without (B) $100 \mathrm{U} / \mathrm{ml}$ IFN- $\beta$ or (C) $5 \mathrm{ng} / \mathrm{ml}$ IL-12 for the given times, and the phosphorylation on STAT1-Y701 and STAT1-S727 was investigated by western blot. Stat $1^{-1-}$ LAK cells served as negative control and HSC-70 as loading control.

(D) Wild-type LAK cells were treated with different kinase inhibitors targeting CDKs (roscovitine and flavopiridol) or MAPK p38 (BIRB 0796 and SB 203580 ), and the phosphorylation status of STAT1-S727 was determined in a western blot.

(E) CDK8 knockdown in primary NK cells with two hairpins led to reduced STAT1-S727 phosphorylation. A random hairpin served as control. 
A

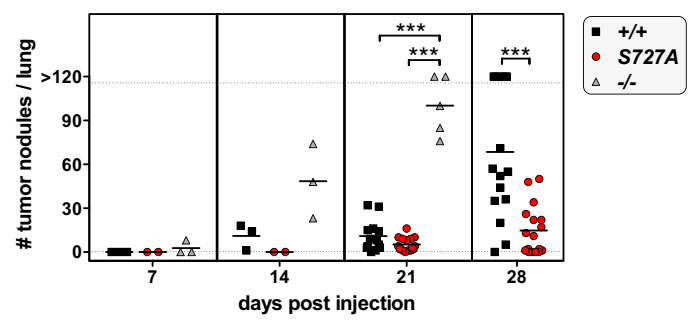

C

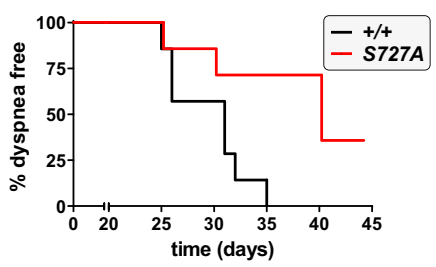

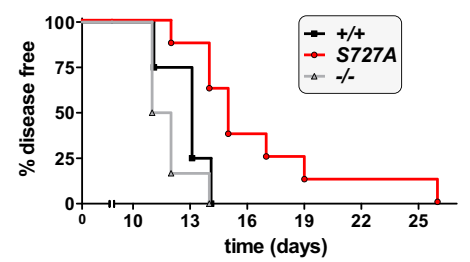

Figure 3. Stat1-S727A Mice Are Less Susceptible to B16F10 Melanoma and v-abl' Leukemic Cells

(A) Wild-type, Stat1-S727A, and Stat1 ${ }^{-1-}$ mice were injected intravenously with B16F10 melanoma cells. At the indicated time points, mice were sacrificed, and tumor nodules visible on the lung surface were counted. Each symbol represents an individual mouse; horizontal lines indicate the mean ${ }^{* \star *} p<0.001$, one-way ANOVA and Tukey's post hoc test on day 21, unpaired $t$ test on day 28).

(B) Representative lung photographs at the indicated time points after injection of B16F10 melanoma cells are shown.

(C) Kaplan-Meier plot of wild-type $(n=7)$ and Stat1-S727A $(n=7)$ mice intravenously injected with B16F10 melanoma cells is illustrated. Log rank testing revealed a significant difference in the onset of dyspnea ( $p=0.027$; MST wild-type $=31$ days; MST Stat1-S727A $=40$ days).

(D) Kaplan-Meier plot of wild-type $(n=8)$, Stat1-S727A $(n=8)$, and Stat1 ${ }^{-1-}(n=6)$ recipient animals inoculated intravenously with $v$-ab/ ${ }^{+}$leukemic cells is presented. Stat1-S727A mice succumb to leukemia with an increased latency (MST $=15$ days) than wild-type $\left(\mathrm{MST}=13\right.$ days) and Stat ${ }^{-1-}(\mathrm{MST}=11.5$ days) animals. Log rank test was corrected with Bonferroni for multiple testing and revealed a significant difference between Stat1-S727A and wild-type ( $p=0.0053)$ and between Stat1-S727A and Stat1 ${ }^{-1-}$ animals $(\mathrm{p}=0.0023)$.

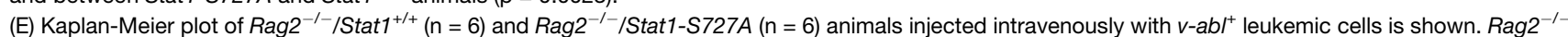
/Stat1-S727A mice succumb to leukemia with increased latency $\left(\mathrm{MST}=14\right.$ days) than Rag2 ${ }^{-/-} /$Stat $1^{1 /+}(\mathrm{MST}=12$ days) animals. Log rank test was statistically significant $(p=0.017)$.

See also Figure S3.

metastasis formation, we transplanted $4 \mathrm{~T} 1$ cells into Rag2 ${ }^{-/-}$ and $\mathrm{Rag}^{-1-} / 1 / 2 \mathrm{rg}^{-1-}$ recipients. Twenty-eight days postinoculation, Rag2 $2^{-1-} / 1 / 2 \mathrm{rg}^{-/-}$mice showed increased metastatic lung infiltrates compared to wild-type and $\operatorname{Rag}^{-1-}$ animals (Figure S4).

\section{DISCUSSION}

Our study reveals an inhibitory role of STAT1-S727 phosphorylation for NK cell cytotoxicity. STAT1-S727 is constitutively phosphorylated in unstimulated NK cells, where it modulates their activity.

The transactivation domain of all STAT proteins except STAT2 harbors at least one conserved serine-phosphorylation site. Experiments in Stat1-S727A-mutated NK cells show that STAT1-S727 phosphorylation is a prerequisite for full IFN- $\gamma$ induction, although it decreases granzyme B and perforin transcription. Perforin function shows a pronounced gene-dosage
B

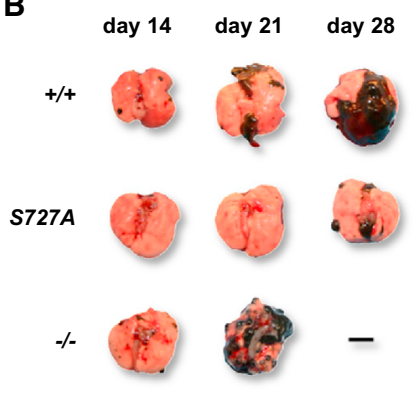

E

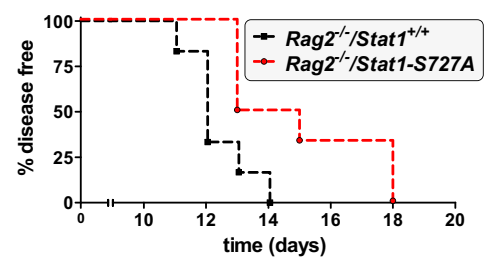

effect: $P r f 1^{+/}$NK cells display reduced cytotoxicity (Lowin et al., 1994). Higher perforin levels may thus lead to higher cytotoxicity, as we observed in Stat1-S727A NK cells. Cytotoxicity might also be affected by additional mechanisms such as a reduction of the inhibitory KLRG1 or an increase in expression of partially activating NKG2A/C/E.

Several kinases phosphorylate STAT1-S727 upon stimulation, depending on cell type and stimulus (Kovarik et al., 1999; Nair et al., 2002; Deb et al., 2003; Bancerek et al., 2013). The transactivation domain of STAT1 is also phosphorylated on S708, S744, and S747. Phosphorylation on S708 has been attributed to IKKe and is indispensable for antiviral IFN signaling (Tenoever et al., 2007).

. Is is illustrated. Log rank testing revealed 
A

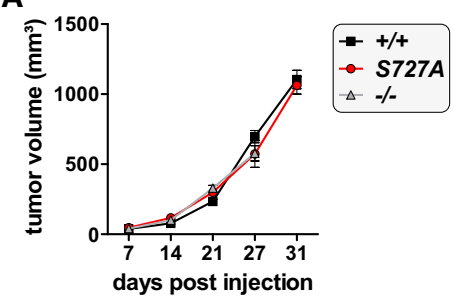

C

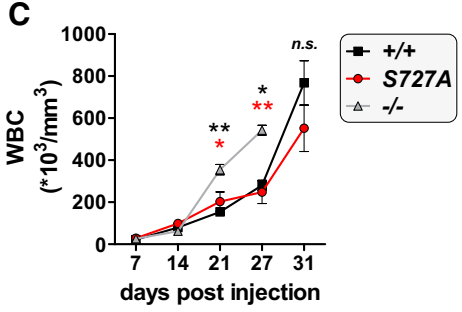

E

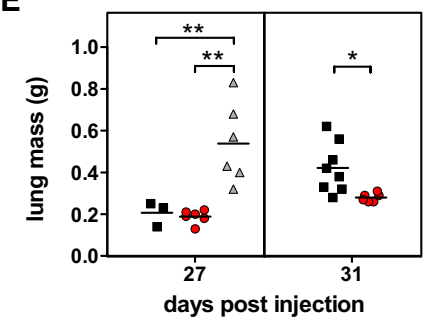

B

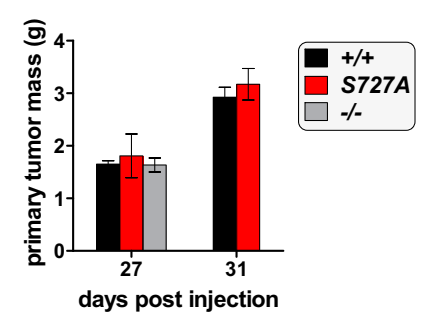

D

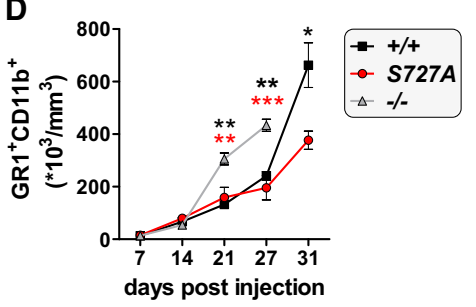

$\mathbf{F}$

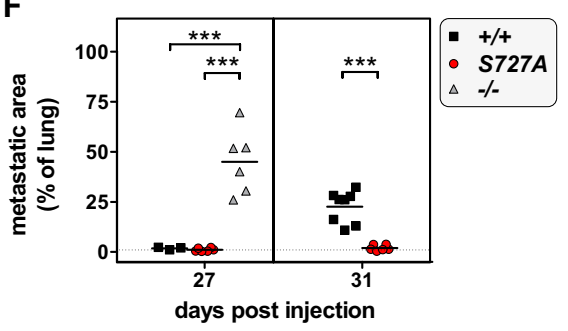

Figure 4. Stat1-S727A Mice Are Resistant to 4T1 Breast Cancer Metastasis into Lungs Wild-type $(n=11)$, Stat1-S727A $(n=12)$, and Stat1 ${ }^{-1-}(n=6)$ animals received orthotopical transplants of $4 \mathrm{~T} 1$ breast cancer cells.

(A) Primary tumor volumes were measured weekly. Symbols represent mean, and error bars indicate SEM.

(B) Some recipients were sacrificed at day 27 (wildtype $n=3$, Stat1-S727A $n=6$, Stat ${ }^{-1-} n=6$ ) and remaining recipients at day 31 , then the primary tumors were weighed. Bar graph depicts mean \pm SEM.

(C and D) Recipient mice were bled weekly, and (C) WBCs and (D) MDSCs (GR1 $\left.{ }^{+} \mathrm{CD} 11 \mathrm{~b}^{+}\right)$were counted $\left({ }^{*} p<0.05,{ }^{\star *} p<0.01,{ }^{* * *} p<0.001\right.$; one-way ANOVA and Tukey's post hoc test on days 21 and 27; unpaired t test on day 31). Symbols represent means, and error bars indicate SEM. n.s., not significant.

( $E$ and F) After termination of the experiment, (E) lungs were weighed, and $(F)$ the percentage (\%) of metastatic area in the lung was determined histochemically $\left({ }^{\star} p<0.05,{ }^{\star *} p<0.01,{ }^{* \star *} p<0.001\right.$; oneway ANOVA and Tukey's post hoc test on day 27; unpaired $t$ test on day 31). Each symbol represents an individual mouse; horizontal lines indicate the mean.

(G) Representative H\&E-stained lung sections of Stat $1^{-1-}$ animals at day 27 and wild-type and Stat1-S727A animals at day 31 post transplantation are shown.

See also Figure S4.

G

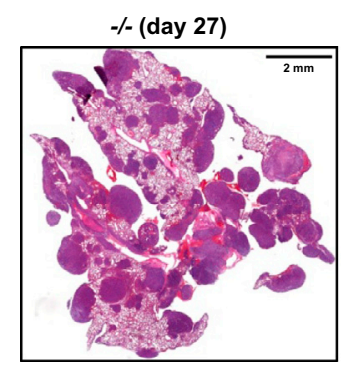

S727A (day 31)

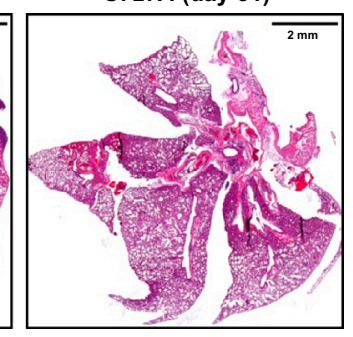

generate NK cells primed to kill more efficiently raises the hope of enhancing clinical efficacy and outcome.

\section{EXPERIMENTAL PROCEDURES}

Mice

$\mathrm{BALB} / \mathrm{c}$ and C57BL/6 wild-type ${ }^{(+/+)}$, Stat1 ${ }^{-/-}$ (Durbin et al., 1996), Stat1-S727A (Varinou et al.,

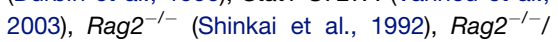

phosphorylation, which is observed in NK cells even in the absence of cytokines and with no concomitant tyrosine (Y701) phosphorylation. We show that S727 phosphorylation exerts a negative influence and show that a biological response is restricted by STAT1-S727 phosphorylation independent of IFN signaling. The Stat1-S727A mutant acts as a hypermorphic rather than a hypomorphic allele of Stat1 in NK cells. Knockdown of CDK8 verified its essential role for basal STAT1-S727 phosphorylation in NK cells and significantly enhanced cytotoxicity. NK cells derived from Stat1-S727A mice are exceptionally cytotoxic and display signs of hyperactivity. Stat1-S727A mice are less susceptible to B16F10 melanoma and $v-a b l^{+}$leukemia and are even resistant to $4 \mathrm{~T} 1$ breast cancer metastasis. Hence, specific CDK8 kinase inhibitors may be useful in tumor therapy. A combination of classical pharmacological target intervention and novel immune cell-based strategies may be able to address the complex nature of cancer immunology. The ability to
Stat1-S727A, Rag2 ${ }^{-/} / / 12 \mathrm{rg}^{-/-}$(Cao et al., 1995), Ifng ${ }^{-/-}$(Dalton et al., 1993), and Ink4a ${ }^{-1-}$ (Serrano et al., 1996) mice were maintained under pathogen-free conditions. The in vitro and B16F10 in vivo experiments were performed with mice on C57BL/6 background. For $v-a b l^{+}$and $4 \mathrm{~T} 1$ tumor models, mice on BALB/c background were used. All experiments were carried out with gender- and age-matched 6- to 12-week-old mice, were approved by the institutional ethics committee, and conform to Austrian laws (license $66.009 / 0019-\mathrm{II} / 10 \mathrm{~b} / 2010$ 14.1.10).

\section{Inhibitor Studies and shRNA Knockdown}

Web-based inquiries, e.g., Group-based Prediction System (GPS; http://gps. biocuckoo.org/) and KinasePhos 2.0 (http://kinasephos2.mbc.nctu.edu.tw/ index.html), were performed. For inhibitor studies, LAK cells were deprived of IL-2 for $3 \mathrm{hr}$ prior to $4 \mathrm{hr}$ treatment with $30 \mu \mathrm{M}$ DMSO (Carl Roth), $100 \mathrm{ng} / \mathrm{ml}$ anisomycin (Sigma-Aldrich), $5 \mu \mathrm{M}$ roscovitine (Calbiochem), $0.5 \mu \mathrm{M}$ flavopiridol (Sigma-Aldrich), $1 \mu \mathrm{M}$ BIRB 0796 (Böhringer Ingelheim), or $25 \mu \mathrm{M}$ SB 203580 (Sigma-Aldrich).

For shRNA-mediated knockdown of CDK8, five pGIPZ clones (RMM4532NM_001260) and two TRC clones (TRCN0000023107 and TRCN 
0000023268) were obtained from Open Biosystems. The best knockdown efficiency was shown by clone 3 for pGIPZ (V2LMM_192695) and clone TRCN0000023268 for TRC. A clone containing a validated nonsilencing shRNA (RHS4346 for pGIPZ and RHS4080 for TRC) served as control. VSVG-pseudotyped lentiviruses were produced as described previously (Hoermann et al., 2011). Recombinant lentiviruses were produced in HEK293T cells with pGIPZ vectors and plasmids encoding GAG-POL and VSV-G. NK cells were transduced by spin infection $\left(800 \times g, 90 \mathrm{~min}, 32^{\circ} \mathrm{C}\right)$ in the presence of $7 \mu \mathrm{g} / \mathrm{ml}$ Polybrene (Sigma-Aldrich) and selected with $2 \mu \mathrm{g} / \mathrm{ml}$ puromycin (Invivogen/Eubio) for 5 days.

\section{In Vitro Cytotoxicity Assay}

Standard $4 \mathrm{hr}\left[{ }^{51} \mathrm{Cr}\right]$-release assays and flow cytometry-based cytotoxicity assays (Zebedin et al., 2008; Schuster et al., 2011) are described in detail in the Extended Experimental Procedures.

\section{B16F10 Tumor Model}

Mice were injected via tail vein with $5 \times 10^{4}$ B16F10 melanoma cells and sacrificed after 7, 14, 21, or 28 days (time course) or at the first sign of dyspnea (Kaplan-Meier). Stat $1^{-/-}$mice were included only until day 21. Lungs were removed, weighed, and captured on camera, and the visible tumor nodules on their surface were counted.

\section{Leukemia Model}

Single-cell suspensions from BALB/c bone marrow were infected with A-MuLV retrovirus in the presence of $7 \mu \mathrm{g} / \mathrm{ml}$ Polybrene (Sigma-Aldrich) and $10 \mathrm{ng} / \mathrm{ml} \mathrm{rmlL-7} \mathrm{(PeproTech)} \mathrm{to} \mathrm{establish} \mathrm{stable} \mathrm{cell} \mathrm{lines.} \mathrm{After} \mathrm{intravenous}$ injection of $10^{5} \mathrm{v}-a b l^{+}$leukemic cells, mice were checked daily for the onset of leukemia and sacrificed at the first sign of disease. They were analyzed for spleen and liver weight and the presence of leukemic cells $\left(\mathrm{CD} 19^{+} \mathrm{CD} 43^{+} \mathrm{B} 220^{+}\right)$in bone marrow, spleen, and blood.

\section{T1 Tumor Model}

A total of $5 \times 10^{5}$ tumor cells $/ 30 \mu$ l PBS was injected in the fat pad of the fifth pair of mammary glands of sedated mice. Once a week, tumor volumes were measured (tumor volume $=\left(\right.$ width $^{2} \times$ length) $\left./ 2\right)$ and WBCs determined in an animal blood counter (Scil Animal Care). GR $1^{+}$CD $11 b^{+}$MDSCs in the blood were assessed via flow cytometry. At the indicated time points, lungs were excised, paraformaldehyde fixed, and paraffin embedded, and six to ten sections $(3 \mu \mathrm{m})$ were stained with hematoxylin and eosin (H\&E, Microm HMS 740 Robot Stainer; Thermo Scientific) and scanned with a Zeiss MIRAX scanner. The percentage of metastatic lung area was quantified by Definiens Analyst software.

\section{Statistical Analysis}

Statistical analysis was performed using GraphPad Prism version 5.00 for Windows (GraphPad Software; http://www.graphpad.com). Where ANOVA showed a statistical difference, Tukey's multiple comparison testing was applied. Comparison of more than two survival curves was made by the Bonferroni correction of log rank tests. The $\alpha$ level for all tests was set to 0.05 , and $p$ values were two tailed. The significance level is indicated for each experiment (in general: ${ }^{*} p<0.05 ;{ }^{* *} p<0.01 ;{ }^{* \star *} p<0.001$ ).

For further details, see the Extended Experimental Procedures and Table S2.

\section{SUPPLEMENTAL INFORMATION}

Supplemental Information includes Extended Results, Extended Experimental Procedures, four figures, and two tables and can be found with this article online at http://dx.doi.org/10.1016/j.celrep.2013.07.012.

\section{ACKNOWLEDGMENTS}

We are indebted to S. Fajmann, S. Wienerroither, M. Parrini, K. Schelch, M. Mair, M. Prchal-Murphy, and B. Strobl for support and scientific input and G. Tebb for careful reading and revision of the manuscript. We are grateful to the mouse facility. The work was supported by the Austrian Academy of Science DOC-fFORTE fellowship (to E.M.P.; http://stipendien.oeaw.ac.at/en), the Austrian Science Fund FWF grant SFB F28 (to M.M., T.D., and V.S.; http://www.fwf.ac.at/en/projects/sfb.html), and the GEN-AU program "Austromouse" of the Austrian Federal Ministry of Science and Research (to M.M.; http://www.gen-au.at/projekt.jsp?projektld=110\&lang=en).

Received: August 9, 2012

Revised: February 6, 2013

Accepted: July 11, 2013

Published: August 8, 2013

\section{WEB RESOURCES}

The URLs for data presented herein are as follows:

Austrian Academy of Science DOC-fFORTE fellowship, http://stipendien. oeaw.ac.at/en

Austrian Science Fund FWF grant SFB F28, http://www.fwf.ac.at/en/projects/ sfb.html

GEN-AU program "Austromouse" of the Austrian Federal Ministry of Science and Research, http://www.gen-au.at/projekt.jsp?projektld=110\&lang=en

GPS, http://gps.biocuckoo.org/
GraphPad Software, http://www.graphpad.com
KinasePhos 2.0, http://kinasephos2.mbc.nctu.edu.tw/index.html

GPS, http://gps.biocuckoo.org/
GraphPad Software, http://www.graphpad.com
KinasePhos 2.0, http://kinasephos2.mbc.nctu.edu.tw/index.html

GPS, http://gps.biocuckoo.org/
GraphPad Software, http://www.graphpad.com
KinasePhos 2.0, http://kinasephos2.mbc.nctu.edu.tw/index.html

\section{REFERENCES}

Bancerek, J., Poss, Z.C., Steinparzer, I., Sedlyarov, V., Pfaffenwimmer, T., Mikulic, I., Dölken, L., Strobl, B., Müller, M., Taatjes, D.J., and Kovarik, P. (2013). CDK8 kinase phosphorylates transcription factor STAT1 to selectively regulate the interferon response. Immunity 38, 250-262.

Bromberg, J.F., Horvath, C.M., Wen, Z., Schreiber, R.D., and Darnell, J.E., Jr. (1996). Transcriptionally active Stat1 is required for the antiproliferative effects of both interferon alpha and interferon gamma. Proc. Natl. Acad. Sci. USA 93, 7673-7678.

Cao, X., Shores, E.W., Hu-Li, J., Anver, M.R., Kelsall, B.L., Russell, S.M., Drago, J., Noguchi, M., Grinberg, A., Bloom, E.T., et al. (1995). Defective lymphoid development in mice lacking expression of the common cytokine receptor gamma chain. Immunity 2, 223-238.

Dalton, D.K., Pitts-Meek, S., Keshav, S., Figari, I.S., Bradley, A., and Stewart, T.A. (1993). Multiple defects of immune cell function in mice with disrupted interferon-gamma genes. Science 259, 1739-1742.

Davis, M.I., Hunt, J.P., Herrgard, S., Ciceri, P., Wodicka, L.M., Pallares, G., Hocker, M., Treiber, D.K., and Zarrinkar, P.P. (2011). Comprehensive analysis of kinase inhibitor selectivity. Nat. Biotechnol. 29, 1046-1051.

Deb, D.K., Sassano, A., Lekmine, F., Majchrzak, B., Verma, A., Kambhampati, S., Uddin, S., Rahman, A., Fish, E.N., and Platanias, L.C. (2003). Activation of protein kinase C delta by IFN-gamma. J. Immunol. 171, 267-273.

Durbin, J.E., Hackenmiller, R., Simon, M.C., and Levy, D.E. (1996). Targeted disruption of the mouse Stat1 gene results in compromised innate immunity to viral disease. Cell 84, 443-450.

Hoermann, G., Cerny-Reiterer, S., Perné, A., Klauser, M., Hoetzenecker, K., Klein, K., Müllauer, L., Gröger, M., Nijman, S.M.B., Klepetko, W., et al. (2011). Identification of oncostatin $M$ as a STAT5-dependent mediator of bone marrow remodeling in KIT D816V-positive systemic mastocytosis. Am. J. Pathol. 178, 2344-2356.

Horvath, C.M., and Darnell, J.E., Jr. (1996). The antiviral state induced by alpha interferon and gamma interferon requires transcriptionally active Stat1 protein. J. Virol. 70, 647-650.

Kaplan, D.H., Shankaran, V., Dighe, A.S., Stockert, E., Aguet, M., Old, L.J., and Schreiber, R.D. (1998). Demonstration of an interferon gamma-dependent tumor surveillance system in immunocompetent mice. Proc. Natl. Acad. Sci. USA 95, 7556-7561. 
Klover, P.J., Muller, W.J., Robinson, G.W., Pfeiffer, R.M., Yamaji, D., and Hennighausen, L. (2010). Loss of STAT1 from mouse mammary epithelium results in an increased Neu-induced tumor burden. Neoplasia 12, 899-905.

Koromilas, A.E., and SexI, V. (2013). The tumor suppressor function of STAT1 in breast cancer. JAKSTAT 2, 1-5.

Kovacic, B., Stoiber, D., Moriggl, R., Weisz, E., Ott, R.G., Kreibich, R., Levy, D.E., Beug, H., Freissmuth, M., and Sexl, V. (2006). STAT1 acts as a tumor promoter for leukemia development. Cancer Cell 10, 77-87.

Kovarik, P., Stoiber, D., Eyers, P.A., Menghini, R., Neininger, A., Gaestel, M., Cohen, P., and Decker, T. (1999). Stress-induced phosphorylation of STAT1 at Ser727 requires p38 mitogen-activated protein kinase whereas IFN-gamma uses a different signaling pathway. Proc. Natl. Acad. Sci. USA 96, 1395613961.

Lee, C.K., Rao, D.T., Gertner, R., Gimeno, R., Frey, A.B., and Levy, D.E. (2000). Distinct requirements for IFNs and STAT1 in NK cell function. J. Immunol. 165, 3571-3577.

Lodolce, J.P., Boone, D.L., Chai, S., Swain, R.E., Dassopoulos, T., Trettin, S., and $\mathrm{Ma}$, A. (1998). IL-15 receptor maintains lymphoid homeostasis by supporting lymphocyte homing and proliferation. Immunity 9, 669-676.

Lowin, B., Beermann, F., Schmidt, A., and Tschopp, J. (1994). A null mutation in the perforin gene impairs cytolytic T lymphocyte- and natural killer cell-mediated cytotoxicity. Proc. Natl. Acad. Sci. USA 91, 11571-11575.

Lucas, M., Schachterle, W., Oberle, K., Aichele, P., and Diefenbach, A. (2007). Dendritic cells prime natural killer cells by trans-presenting interleukin 15 . Immunity 26, 503-517.

Nair, J.S., DaFonseca, C.J., Tjernberg, A., Sun, W., Darnell, J.E., Jr., Chait, B.T., and Zhang, J.J. (2002). Requirement of Ca2+ and CaMKII for Stat1 Ser-727 phosphorylation in response to IFN-gamma. Proc. Natl. Acad. Sci. USA 99, 5971-5976.

Nguyen, K.B., Salazar-Mather, T.P., Dalod, M.Y., Van Deusen, J.B., Wei, X.Q., Liew, F.Y., Caligiuri, M.A., Durbin, J.E., and Biron, C.A. (2002). Coordinated and distinct roles for IFN-alpha beta, IL-12, and IL-15 regulation of NK cell responses to viral infection. J. Immunol. 169, 4279-4287.

Pilz, A., Kratky, W., Stockinger, S., Simma, O., Kalinke, U., Lingnau, K., von Gabain, A., Stoiber, D., Sexl, V., Kolbe, T., et al. (2009). Dendritic cells require STAT-1 phosphorylated at its transactivating domain for the induction of peptide-specific CTL. J. Immunol. 183, 2286-2293.

Robbins, S.H., Tessmer, M.S., Van Kaer, L., and Brossay, L. (2005). Direct effects of T-bet and MHC class I expression, but not STAT1, on peripheral NK cell maturation. Eur. J. Immunol. 35, 757-765.

Sadzak, I., Schiff, M., Gattermeier, I., Glinitzer, R., Sauer, I., Saalmüller, A. Yang, E., Schaljo, B., and Kovarik, P. (2008). Recruitment of Stat1 to chromatin is required for interferon-induced serine phosphorylation of Stat1 transactivation domain. Proc. Natl. Acad. Sci. USA 105, 8944-8949.

Schneckenleithner, C., Bago-Horvath, Z., Dolznig, H., Neugebauer, N., Kollmann, K., Kolbe, T., Decker, T., Kerjaschki, D., Wagner, K.-U., Müller, M., et al. (2011). Putting the brakes on mammary tumorigenesis: loss of STAT1 predisposes to intraepithelial neoplasias. Oncotarget 2, 1043-1054.

Schroder, K., Spille, M., Pilz, A., Lattin, J., Bode, K.A., Irvine, K.M., Burrows, A.D., Ravasi, T., Weighardt, H., Stacey, K.J., et al. (2007). Differential effects of CpG DNA on IFN-beta induction and STAT1 activation in murine macrophages versus dendritic cells: alternatively activated STAT1 negatively regulates TLR signaling in macrophages. J. Immunol. 179, 3495-3503.

Schuster, C., Berger, A., Hoelzl, M.A., Putz, E.M., Frenzel, A., Simma, O., Moritz, N., Hoelbl, A., Kovacic, B., Freissmuth, M., et al. (2011). The cooperating mutation or "second hit" determines the immunologic visibility toward MYCinduced murine lymphomas. Blood 118, 4635-4645.

Serrano, M., Lee, H., Chin, L., Cordon-Cardo, C., Beach, D., and DePinho, R.A (1996). Role of the INK4a locus in tumor suppression and cell mortality. Cell 85, 27-37.

Shinkai, Y., Rathbun, G., Lam, K.P., Oltz, E.M., Stewart, V., Mendelsohn, M. Charron, J., Datta, M., Young, F., Stall, A.M., et al. (1992). RAG-2-deficient mice lack mature lymphocytes owing to inability to initiate $V(D) J$ rearrangement. Cell 68, 855-867.

Stark, G.R.R., and Darnell, J.E.E., Jr. (2012). The JAK-STAT pathway at twenty. Immunity 36, 503-514.

Stoiber, D., Kovacic, B., Schuster, C., Schellack, C., Karaghiosoff, M., Kreibich, R., Weisz, E., Artwohl, M., Kleine, O.C., Müller, M., et al. (2004). TYK2 is a key regulator of the surveillance of B lymphoid tumors. J. Clin. Invest. 114, 1650-1658.

Tenoever, B.R., Ng, S.L., Chua, M.A., McWhirter, S.M., García-Sastre, A., and Maniatis, T. (2007). Multiple functions of the IKK-related kinase IKKepsilon in interferon-mediated antiviral immunity. Science 315, 1274-1278.

Varinou, L., Ramsauer, K., Karaghiosoff, M., Kolbe, T., Pfeffer, K., Müller, M., and Decker, T. (2003). Phosphorylation of the Stat1 transactivation domain is required for full-fledged IFN-gamma-dependent innate immunity. Immunity 19, 793-802.

Vivier, E., Raulet, D.H., Moretta, A., Caligiuri, M.A., Zitvogel, L., Lanier, L.L., Yokoyama, W.M., and Ugolini, S. (2011). Innate or adaptive immunity? The example of natural killer cells. Science 331, 44-49.

Wang, P., Gu, Y., Zhang, Q., Han, Y., Hou, J., Lin, L., Wu, C., Bao, Y., Su, X. Jiang, M., et al. (2012). Identification of resting and type I IFN-activated human NK cell miRNomes reveals microRNA-378 and microRNA-30e as negative regulators of NK cell cytotoxicity. J. Immunol. 189, 211-221.

Watford, W.T., Hissong, B.D., Bream, J.H., Kanno, Y., Muul, L., and O'Shea, J.J. (2004). Signaling by IL-12 and IL-23 and the immunoregulatory roles of STAT4. Immunol. Rev. 202, 139-156.

Wen, Z., Zhong, Z., and Darnell, J.E., Jr. (1995). Maximal activation of transcription by Stat 1 and Stat3 requires both tyrosine and serine phosphorylation. Cell 82, 241-250.

Zebedin, E., Simma, O., Schuster, C., Putz, E.M., Fajmann, S., Warsch, W., Eckelhart, E., Stoiber, D., Weisz, E., Schmid, J.A., et al. (2008). Leukemic challenge unmasks a requirement for PI3Kdelta in NK cell-mediated tumor surveillance. Blood 112, 4655-4664. 